\title{
Wolaytta Language
}

National Cancer Institute

\section{Source}

National Cancer Institute. Wolaytta Language. NCI Thesaurus. Code C154194.

An Afro-Asiatic language spoken in the Wolayita Zone and some other parts of the Southern Nations, Nationalities, and People's Region of Ethiopia. 